\title{
Integrating principles of developmental biology in tissue engineering of heart valves
}
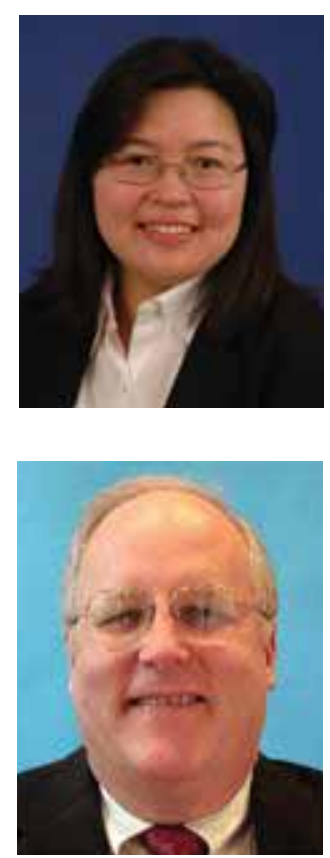

VimaL Sales \& Jdm E Mayer Jr

${ }^{\dagger}$ Author for correspondence Children's H ospital Boston, D epartment of Cardiovascular Surgery, 300 Longwood Avenue, Boston, M A 02115, USA Tel.: +1 617919 2922; Fax: +1 617730 0214; virna.sales@cardio.chboston. org

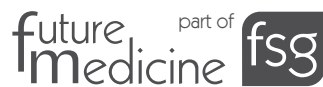

'The ideal heart valve replacement would not only be biocompatible, rea dily available and incredibly durable, but also have the potential for growth.'

Approximately eight out of every thousand infants are born with congenital heart disease. The majority of these defects involve malformations or absence of the pulmonary valve and main pulmonary arteries. Although repair early in life is possible, the procedure often requires the use of a replacement valve. Current replacement options include prosthetic and bioprosthetic valves; however, these replacements have limited durability and are subject to calcification, thrombosis and a lack of growth potential [1]. Children, therefore, face an ongoing morbidity due to the limitations of these replacement valves and must endure multiple follow-up operations in order to place progressively larger valves to accommodate their growth. Tissue engineering offers the potential to create a living valve with the capacity for growth and self-repair, and which is resistant to infection. Tissue engineering is defined as an interdisciplinary field that applies the principles of engineering and life sciences toward the development of biological substitutes that restore, maintain or improve function [2]. This approach is based on seeding autologous cells onto biodegradable scaffolds or decelullarized biological matrices in order to provide temporary structural support and organization until the cells synthesize their own extracellular matrix. Previous studies by our group and others have demonstrated in vivo results culminating in the creation of single-valve leaflets [3], vascular grafts $[4,5]$ and trileaflet-valved conduits [6-11]. These tissue-engineered heart valve (TEHV) structures have been created using vascular cells $[3,4,6-9]$, umbilical bloodderived endothelial progenitor cells [11] and noncirculating bone marrow-derived mesenchymal stem cells $[12,13]$ as cell sources. O ur group and others have also demonstrated results in preliminary in vivo experiments. However, many questions remain unanswered:

- What is the optimal cell source?

- How will the scaffold material influence tissue growth and allow favorable scaffold cell and extracellular matrix interactions?

- What in vitro conditions provide the most cell growth?

- What is the timeframe for in vivo maturation?

The ideal heart valve replacement would not only be biocompatible, readily available and incredibly durable, but also have the potential for growth [14]. Although the ultimate goal of TEHV is to recapitulate the matrix and cells found in the native tissue, variabilities exist within the potential strategies and sources of cells. A widely accepted paradigm of tissue engineering comprises of a scaffold that is preseeded with cells, followed by an in vitro stage of tissue formation typically conducted in a bioreactor (that recapitulates a physiological metabolic and mechanical environment) and, following subsequent implantation of the construct, an in vivo stage of tissue growth and remodeling [15].

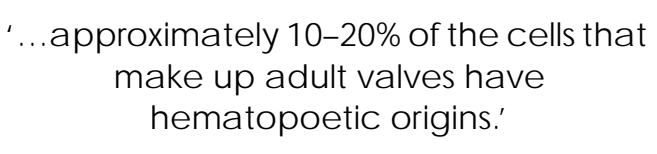

Unresolved issues

Cell source

Moving towards clinical applications, less invasively accessible cells, such as circulating and umbilical-derived endothelial progenitor cells [11] and bone marrow-derived mesenchymal stem cells $[12,13]$ have shown promising results for TEHVs. Although their pluripotency and multipotency potential is enormous, we still do not fully understand how soluble hormones, extracellular matrix proteins, other cells and physical factors control stem cell fate switching in distinct tissue microenvironments. This information is crucial before we can develop clinically applicable T EH V s using stem 
cells as cell sources [16]. Recently, it was demonstrated that approximately $10-20 \%$ of the cells that make up adult valves have hematopoetic origins. This suggests that stem cells may be able to repopulate valvular tissues and recapitulate valvular cell phenotypes. H owever, where to target along the continuous spectrum of valvular cell phenotypes and how to stimulate the desired mature phenotype remains unknown $[17,18]$.

\section{Scaffold material}

The tissue-engineered biomaterial scaffolds need to be biocompatible and bioresorbable and should be designed for optimized scaffold architecture (pore size, morphology and surface topography) in order to enhance oxygen diffusion and support cell and tissue growth. In addition, they must also exhibit the desired degradation rate and suitable mechanical and structural properties comparable with the native tissue they replace, from the time of implantation through the lifetime of the recipient. This implies central requirements of relatively constant mechanical properties despite potentially considerable tissue remodeling and scaffold resorption [15]. Therefore, should we fabricate biomaterials to construct microenvironments that mimic embryonic organs, healing wounds or developmentally active inducer tissues [16]? Powerful methods of fabricating tissue-engineering scaffolds could include $[16,19,20]$ :

- Engineering the surface topography of these scaffolds at the micrometer and nanometer scales to produce optimized cellular responses;

- Developing injectable self-assembling nanomaterials;

- Incorporating biological signals into the nanostructured scaffolds to create healing microenvironments that harness the body's own stem cells, tissue-specific chemical factors and cell-generated traction forces.

Electrospun nanofibrous scaffolds have al so been shown to exhibit highly mechanical properties that resemble native pulmonary heart valve cusps [21].

\section{In vitro conditioning}

$M$ echanical and biological stimulation during in vitro tissue development are utilized in TEH V s for improving tissue formation, organization and cellular function. The bioreactor exposes the developing tissue to mechanical conditioning, such as flow, shear stress and/or strain. O ne type of bioreactor used in the construction of TEH Vs is the pulse duplicator, which provides pressure and flow to the developing TEHV, subsequently promoting mechanical strength and cellular organization in the engineered tissues $[6,22]$. H owever, there is increasing evidence that hemodynamics regulate valvulogenesis [23]. That is, mechanical forces may play a role in the maturation of developing a TEH V. Should we focus on engineering adult valve structures and then strengthen them through mechanical conditioning or, instead, preferably create immature developmental tissue and stimulate maturation by using the embryonic hemodynamic regime [18]?

\section{In vivo maturation}

We and others have provided proof-of-concept studies demonstrating growth and remodeling of the engineered construct to a trilaminar structure, resembling the normal architecture and biology of cardiac valves, which functions satisfactorily in vivo for more than 4-8 months following implantation $[6,9,13]$. The in vivo mechanical environment presumably contributes to the ingrowth and tissue remodeling, and results in normal valve architecture $[15,24]$. Can these tissue-engineered structures remain viable, sustain the wear and tear of normal circulation over a lifetime and grow in pediatric patients [14]? There are numerous challenges to overcome before this technology can be translated to a clinical setting [25].

\footnotetext{
'Tissue engineering offers the potential to create a living valve with the capacity for growth and self-repair, and which is resistant to infection.'
}

\section{Future perspective}

Developmental biology approach in TEHV In embryonic cardiac valves, explants of endocardial cushion tissue undergo endothelial to mesenchymal transdifferentiation when valve endothelial cells invade the cardiac jelly (extracellular matrix). Functional cardiac valve formation involves dynamic and continuing interactions between cells and the hyaluronanrich 'cardiac jelly', which are necessary for the proper chamber separation and valve-leaflet development. Therefore, it appears likely that the spatial and temporal presence of hyaluronan with specific proteoglycans and growth 
factors will promote the switch in cell signaling machinery that facilitates the maturation of heart valves [26-28]. Biochemical and biomechanical signals that guide normal fetal cardiac valve development will likely have similar effects during the formation of TEH V. M anipulation of these signals can favorably influence the development of TEH V formed from cells and biodegradable scaffolds. By identifying and engineering microenvironmental cues provided in embryonic cardiac valve development, we can perhaps recapitulate these programmed morphogenetic events and guide cellular behavior toward the formation of appropriate tissue for a normal cardiac valve. The fundamental principles of developmental processes will advance our understanding of the factors affecting in vitro TEH V development and how this translates into the in vivo performance of engineered heart valves. If the TEH V can become a reality, it will significantly change the treatment paradigm for children with congenital heart diseases.

Financial \& competing interests disclosure This work was supported by NIH grants HL-60463. JE M ayer is a recipient of TEPH A/N ational Institutes of Standards and Technology (N IST N AN B2H 3053), Gross Cardiovascular and Tissue Engineering D onor Funds and Center for Integration of M edicine and Innovative Technology (CIMIT). Virna $L$ Sales is the recipient of the American $\mathrm{H}$ eart Association $\mathrm{N}$ ational Scientist Development $G$ rant 0635620T. The authors have no other rele vant affiliations or financial involvement with any organization or entity with a financial interest in or financial conflict with the subject matter or materials discussed in the manuscript apart from those disclosed.

The authors acknowledge editorial expertise of Michael Blaze, PhD.
Bibliography

1. Castaneda AR Jr, Jonas RA, M ayer JE, $H$ anley $F L(E d s)$.: In: Cardiac Surgery of the N eonate and Infant. W B Saunders, NY, USA (1994).

2. Langer $R$, Vacanti JP: Tissue engineering. Science 260(5110), 920-926 (1993).

3. Shinoka T, Breuer CK, Tanel RE et al.: $T$ issue engineering heart valves: valve leaflet replacement study in a lamb model. Ann. Thorac. Surg. 60(Suppl. 6), S513-S516 (1995).

4. Shinoka T, Shum-Tim D, M a PX et al.: $C$ reation of viable pulmonary artery autografts through tissue engineering. J. Thorac. Cardiovasc. Surg. 115(3), 536-545; discussion 545-536 (1998).

5. H oerstrup SP, Kadner A, Breymann C et al.: Living, autologous pulmonary artery conduits tissue engineered from human umbilical cord cells. Ann. Thorac. Surg. 74(1), 46-52; discussion 52 (2002).

6. H oerstrup SP, Sodian R, D aebritz $S$ et al.: Functional living trileaflet heart valves grown in vitro. Circulation 102(19 Suppl. 3), III44-III49 (2000).

7. Sodian R, H oerstrup SP, Sperling JS et al.: Early in vivo experience with tissueengineered trileaflet heart valves. Circulation 102(19 Suppl. 3), III22-III29 (2000).

8. Sodian R, H oerstrup SP, Sperling JS et al.: Tissue engineering of heart valves: in vitro experiences. Ann. Thorac. Surg. 70(1), 140-144 (2000).

9. Steinhoff $G$, Stock $U, K$ arim $N$ et al.: Tissue engineering of pulmonary heart valves on allogenic acellular matrix conduits: in vivo restoration of valve tissue. Circulation 102(19 Suppl. 3), III50-III55 (2000).

10. Cebotari $\mathrm{S}, \mathrm{M}$ ertsching $\mathrm{H}$, Kallenbach $\mathrm{K}$ et al.: C onstruction of autologous human heart valves based on an acellular allograft matrix. Circulation 106(12 Suppl. 1), 163-I68 (2002).

11. Schmidt $D, M$ ol $A$, Breymann $C$ et al.: Living autologous heart valves engineered from human prenatally harvested progenitors. Circulation 114(Suppl. 1), |125-I131 (2006).

12. H oerstrup SP, Kadner $A, M$ elnitchouk $S$ et al.: Tissue engineering of functional trileaflet heart valves from human marrow stromal cells. Circulation 106(12 Suppl. 1), |143-I 150 (2002).

13. Sutherland FW, Perry TE, Yu Y et al.: From stem cells to viable autologous semilunar heart valve. Circulation 111(21), 2783-2791 (2005).

14. M ayer JE Jr: In search of the ideal valve replacement device. J. Thorac. Cardiovasc. Surg. 122(1), 8-9 (2001).

15. $\mathrm{M}$ endelson $\mathrm{K}$, Schoen $\mathrm{FJ}$ : $\mathrm{H}$ eart val ve tissue engineering: concepts, approaches, progress, and challenges. Ann. Biomed. Eng. 34(12), 1799-1819 (2006).

16. Ingber DE, M ow VC, Butler D et al.: Tissue engineering and developmental biology: going biomimetic. Tissue Eng. 12(12), 3265-3283 (2006).

17. Visconti RP, Ebihara $Y, L a R u e A C$ et al.: $A n$ in vivo analysis of hematopoietic stem cell potential: hematopoietic origin of cardiac valve interstitial cells. Circ. Res. 98(5), 690-696 (2006).

18. Butcher JT, M arkwald RR: Valvulogenesis: the moving target. Philos. Trans. R. Soc. Lond. B Biol. Sci. 362(1484), 1489-1503 (2007).

19. Lutolf M P, H ubbell JA: Synthetic biomaterials as instructive extracellular microenvironments for morphogenesis in tissue engineering. $\mathrm{N}$ at. Biotechnol. 23(1), 47-55 (2005).

20. Pratt $A B$, Weber FE, Schmoekel $H G$ et al.: Synthetic extracellular matrices for in situ tissue engineering. Biotechnol. Bioeng. 86(1), 27-36 (2004).

21. Courtney T, Sacks M S, Stankus J et al.: $D$ esign and analysis of tissue engineering scaffolds that mimic soft tissue mechanical anisotropy. Biomaterials 27(19), 3631-3638 (2006).

22. Breuer CK, M ettler BA, Anthony $T$ et al.: Application of tissue-engineering principles toward the development of a semilunar heart valve substitute. Tissue Eng. 10(11-12), 1725-1736 (2004).

23. Butcher JT, M cQ uinn TC, Sedmera D et al.: Transitions in early embryonic atrioventricular valvular function correspond with changes in cushion biomechanics that are predictable by tissue composition. Circ. Res. 100(10), 1503-1511 (2007).

24. Ingber $D E$, Levin $M:$ W hat lies at the interface of regenerative medicine and developmental biology? D evelopment 134(14), 2541-2547 (2007). 
25. Badylak SF: Regenerative medicine approach to heart valve replacement. Circulation 111(21), 2715-2716 (2005).

26. Eisenberg LM , M arkwald RR: M olecular regulation of atrioventricular valvuloseptal morphogenesis. Circ. Res 77(1), 1-6 (1995).

27. Camenisch TD, Schroeder JA, Bradley J et al.: $\mathrm{H}$ eart-valve mesenchyme formation is dependent on hyaluronan-augmented activation of ErbB2-ErbB3 receptors. $N$ at. M ed. 8(8), 850-855 (2002).
28. Schroeder JA, Jackson LF, Lee DC et al.: Form and function of developing heart valves: coordination by extracellular matrix and growth factor signaling. J. M ol. M ed. 81(7), 392-403 (2003).

Affiliations

- Virna L Sales, M D

Children's H ospital Boston, D epartment of Cardiovascular Surgery, 300 Longwood Avenue, Boston, M A 02115, USA
Tel.: +1 617919 2922;

Fax: +1 617730 0214;

virna.sales@cardio.chboston.org

- John E M ayer Jr, M D

Children's H ospital Boston, D epartment of Cardiovascular Surgery, 300 Longwood Avenue, Boston, M A 02115, U SA

Tel.: +1 617355 8258;

Fax: +1 6177310214 ;

john.mayer@cardio.chboston.org 